\title{
Work related musculoskeletal disorders among surgeons working in a tertiary care hospital in Kathmandu, Nepal
}

\begin{abstract}
: professionals in many sectors. Surgeons are among the most vulnerable as they have to work for long hours in unfavorable posture. Objective: Aim of this study was to determine both prevalence of work related musculoskeletal disorders and types of ailments among surgeons of different sub-specialties in a tertiary care hospital in Kathmandu. Methods: In This cross sectional study was conducted in Bir Hospital, a tertiary care hospital in Kathmandu. A total of 50 surgeons of different sub-specialties were surveyed. Self-reported questionnaires included i) socio-demographic information, ii) Dutch Musculoskeletal Questionnaire on ergonomic hazards and iii) Nordic musculoskeletal disorders questionnaire on pain and discomfort. Data were analyzed using SPSS version 20. Result: Respondents were 40 male and 10 female surgeons with mean age of 38.9 years. Forty-four respondents (88\%) reported that their job usually require them to stand for long hours, and41 (82\%) also reported that they would work in the same posture for long period of time. In addition, $43(86 \%)$ also reported that they would have to bend their trunk slightly during their job. Thirty-five respondents $(70 \%)$ reported having at least one musculoskeletal disorder. Twenty-three (65.7\%) surgeons had to miss their job at least once during last 12 month of which nineteen (54.3\%) missed them in last 7 days. Conclusion: This survey showed that various musculoskeletal ailments were common among surgeons of all sub-specialties in our hospital which is likely one of the common and a serious occupational hazards in this population.
\end{abstract}

Background: Musculoskeletal disorders are common work-related health problems affecting Vaidya $\mathrm{A}^{1}$, Sainju N K ${ }^{2}$, Joshi S K

1National Academy for Medical Science, Bir Hospital

2 Kathmandu Medical College

Key Words: Work related musculoskeletal disorder, surgeons, Nepal

\section{Corresponding Author: \\ Dr. Anira Vaidya \\ Email: aniravaidya@gmail.com}

(c) 2015 IJOSH All rights reserved.

\section{Introduction}

Occupation of surgeons is considered as one of the highies risk profession as they are often exposed to various occupational hazards, such as potential contact with infectious agents as serious as human immunodeficiency virus (HIV), hepatitis $B$, hepatitis $C$, due to needle stick or direct exposure with body secretions like blood, pus, respiratory secretions. They are also at higher risk for frequently being exposed to radiation.[1]Work related ergonomic hazards and associated musculoskeletal disorders are often overlooked despite being very common among surgeons. Likely explanations for high prevalence of work related musculoskeletal disorders (WRMSD) include repetitive movement, static posture for long time, prolonged exposure to ergonomic risk factors.

The term Musculoskeletal disorders (MSD) denotes health problem of locomotor apparatus, i.e. of muscles, tendons, skeleton, cartilage, ligaments and nerves. Musculoskeletal disorders includes all forms of ill-health ranging from light, transient disorder to irreversible \& disabling injuries[2]. There are various factors responsible for developing WRMSD and associated pain[3].Static posture, repetitive movement, suboptimal lighting condition, poor positioning, genetic predisposition, mental stress, physical conditioning, aging and obesity are some of the risk factors which can result in WRMSD including pain[4].

A large number of research have studied global burden of diseases and injuries related to occupation. Annual incidence of MSDs was estimated to comprise almost $1 / 3 \mathrm{rd}$ of all occupational diseases in the world in 1994, which makes MSDs as the most common occupational disease affecting workers throughout the world [5]. 
Among health care providers, surgeons are always at higher risk of developing work related musculoskeletal disorders. There is paucity of study on WRMSD among surgeon in various sub-specialties. The present study aims to determine prevalence of MSDs in surgeon in terms of perception of pain experienced due to the rigors of their respective professional works.

\section{Methods}

This is a cross sectional study conducted via a survey among surgeons working in a tertiary health care centre in Kathmandu.

Self-reporting general questionnaire, Dutch Musculoskeletal Questionnaire [6] and Standard Nordic MSD questionnaire [7], were used for this study. These questionnaires are valid and reliable that include various parameters related to MSD. The survey was conducted among 50 surgeons from various sub-specialties and dental surgeons working in the same hospital. All the surgeons who were working in the hospital actively and full-time basis who volunteered to participate were included in the study. Informed consent was obtained from all the respondents. Data were analyzed by using SPSS version 20.

\section{Results}

The study respondents consisted of 40 male and 10 female surgeons whose mean age was 38.9 years with a range of 29 to 66 years old. They consisted of 22 general surgeons, 7 ENT surgeons, 3 neurosurgeons, 7 orthopedic surgeons, 3 plastic surgeons and 8 dental surgeons. Twenty five (50\%) of them had job experience of less than 6 years. Forty one of them reported regularly consuming alcohol and 13 were smokers.

Data on workplace ergonomic hazards based on Dutch Musculoskeletal questionnaires that have direct effect on MSDs are presented in Table 1.Forty-four respondents (88\%) reported that their job usually require them to stand for long hours, and 41 $(82 \%)$ also reported that they would work in the same posture for long period of time. In addition, 43 (86\%) also reported that they would have to bend their trunk slightly during their job and 41 $(82 \%)$ had to make repetitive movement with arm, hand or finger during their work.
Table 1: Workplace ergonomic hazards based on Dutch Musculoskeletal questionnaires

\begin{tabular}{|c|c|c|c|}
\hline S.N & Workplace ergonomic hazards & Yes & No \\
\hline \multirow[t]{4}{*}{1.} & In the work often have to: & & \\
\hline & -stand for a long periods & 44 & 6 \\
\hline & -walk for long periods & 11 & 39 \\
\hline & -work in the same postures for long periods & 41 & 9 \\
\hline \multirow[t]{6}{*}{2.} & In your work often have to lift: & & \\
\hline & -in an uncomfortable position & 31 & 19 \\
\hline & -with the load for away from your body & 16 & 34 \\
\hline & -with twisted trunk & 29 & 21 \\
\hline & -with the loads above the shoulder level & 20 & 30 \\
\hline & -with a load which is difficult to grip or hold & 20 & 30 \\
\hline \multirow[t]{6}{*}{3.} & In your work often have to: & & \\
\hline & -bent slightly with your trunk & 43 & 7 \\
\hline & -bent heavily with your trunk & 8 & 42 \\
\hline & -twist slightly with your trunk & 36 & 14 \\
\hline & -twist heavily with your trunk & 17 & 33 \\
\hline & -bent and twist simultaneously with your trunk & 30 & 20 \\
\hline \multirow[t]{6}{*}{4.} & In your work often have to work: & & \\
\hline & -in a slightly bent posture for long periods & 38 & 12 \\
\hline & -in a heavily bent posture for long periods & 12 & 38 \\
\hline & - in a slightly twisted posture for long periods & 31 & 19 \\
\hline & - in a heavily twisted posture for long periods & 11 & 39 \\
\hline & - in a bent and twisted for long periods & 15 & 35 \\
\hline \multirow[t]{3}{*}{5.} & In your work often have to: & & \\
\hline & $\begin{array}{l}\text { - bent your wrist or hold your wrist bent for long } \\
\text { periods }\end{array}$ & 36 & 14 \\
\hline & $\begin{array}{l}\text { - twist your wrist or hold your wrist twisted for long } \\
\text { periods }\end{array}$ & 22 & 28 \\
\hline \multirow[t]{4}{*}{6.} & In your work often have to make: & & \\
\hline & $\begin{array}{l}\text {-same movements with your arms, hands or } \\
\text { fingers many times per minutes }\end{array}$ & 22 & 28 \\
\hline & $\begin{array}{l}\text { - same movements bending, twisting with your } \\
\text { trunk many times per minutes }\end{array}$ & 24 & 26 \\
\hline & $\begin{array}{l}\text { - same movements bending, twisting with your } \\
\text { head many times per minutes }\end{array}$ & 33 & 17 \\
\hline \multirow[t]{4}{*}{7.} & In your work often have to: & & \\
\hline & -hold your hands at or under shoulder level & 33 & 17 \\
\hline & -hold your hands above shoulder level & 16 & 34 \\
\hline & - work in uncomfortable posture & 26 & 24 \\
\hline 8. & Normal breaks sufficient? & 35 & 15 \\
\hline 9. & Able to take holiday on wish & 30 & 20 \\
\hline 10. & Your work is physically very strenuous & 27 & 23 \\
\hline 11. & $\begin{array}{l}\text { Your work cause you to perspire or to be out } \\
\text { of breath }\end{array}$ & 17 & 33 \\
\hline 12. & You are mentally exhausted by your work & 26 & 24 \\
\hline 13. & $\begin{array}{l}\text { You feel tired when you wake up at the start of } \\
\text { a new working day }\end{array}$ & 20 & 30 \\
\hline 14. & You feel frustrated by your jobs & 14 & 36 \\
\hline 15. & You mostly enjoy your work & 41 & 9 \\
\hline \multirow[t]{6}{*}{16.} & You are much hindered in your work by & & \\
\hline & -noise & 28 & 22 \\
\hline & -lack of fresh air & 27 & 23 \\
\hline & -dry air & 22 & 28 \\
\hline & -changes or extreme of temperature & 31 & 19 \\
\hline & -bad smells & 35 & 15 \\
\hline
\end{tabular}


Tables 2, 3 and 4 are based on Nordic questionnaire on MSDs. Table 2 shows number of respondents who experienced pain in different body parts in last 12 months. It reveals that thirty-five (70\%) surgeons had at least one MSD. Twenty-one $(60 \%)$ of them complained of pain in lower back, $45 \%$ neck pain, and $34 \%$ elbow pain and so on.

Tables 3 and 4 show the information on respondents who missed their normal work because of pain in last 12 months and 7 days respectively. Twenty-three $(65.7 \%)$ of them missed their normal work at any time during last 12 month and nineteen (54.3\%) during last 7 days.

Table 2. Pain in different body parts in last 12 months

\begin{tabular}{|l|c|c|}
\hline Parts of body where pain occurred & Yes & No \\
\hline Neck & 16 & 34 \\
\hline Shoulders & 11 & 39 \\
\hline Elbows & 12 & 38 \\
\hline Wrists/hands & 10 & 40 \\
\hline Upper back & 9 & 41 \\
\hline Lower back & 21 & 29 \\
\hline Hips/thighs & 7 & 43 \\
\hline Knees & 10 & 40 \\
\hline Ankles/feet & 10 & 40 \\
\hline
\end{tabular}

Table 3: Respondents prevented from doing normal work because of pain in last 12 month

\begin{tabular}{|l|l|l|}
\hline Parts of body where pain occurred & Yes & No \\
\hline Neck & 5 & 45 \\
\hline Shoulders & 6 & 44 \\
\hline Elbows & 3 & 47 \\
\hline Wrists/hands & 6 & 44 \\
\hline Upper back & 3 & 47 \\
\hline Lower back & 9 & 41 \\
\hline Hips/thighs & 2 & 48 \\
\hline Knees & 5 & 45 \\
\hline Ankles/feet & 5 & 45 \\
\hline
\end{tabular}

Table 4: Respondents prevented from doing normal work because of pain in last week

\begin{tabular}{|l|l|l|}
\hline Parts of body where pain occurred & Yes & No \\
\hline Neck & 3 & 47 \\
\hline Shoulders & 3 & 47 \\
\hline Elbows & 1 & 49 \\
\hline Wrists/hands & 6 & 44 \\
\hline Upper back & 5 & 45 \\
\hline Lower back & 6 & 44 \\
\hline Hips/thighs & 3 & 47 \\
\hline Knees & 3 & 47 \\
\hline Ankles/feet & 6 & 44 \\
\hline
\end{tabular}

Table 5 shows higher odds ratios for various MSDs due to exposure to various work related ergonomic hazards. Except for pain in elbow joint due to holding hands above the shoulder level OR $(95 \%$ CI)6.780 (1.140, 40.325), other MSDs were not statistically significant.
Table 5: Odds Ratio (OR) of MSDs due to exposure to work related ergonomic hazards

\begin{tabular}{|l|l|c|}
\hline \multicolumn{1}{|c|}{$\begin{array}{c}\text { Musculoskeletal } \\
\text { Disorders }\end{array}$} & $\begin{array}{c}\text { Work related ergonomic } \\
\text { hazards }\end{array}$ & $\begin{array}{c}\text { Odds Ratio (OR) with } \\
95 \% \text { Confidence Inter- } \\
\text { val (95\% CI) }\end{array}$ \\
\hline Low back pain & $\begin{array}{l}\text { Standing for long period } \\
\text { at work }\end{array}$ & $1.852(.280,12.245)$ \\
\hline Low back pain & $\begin{array}{l}\text { Lift things in an uncom- } \\
\text { fortable position }\end{array}$ & $2.050(.590,7.118)$ \\
\hline Low back pain & $\begin{array}{l}\text { Bent slightly with trunk at } \\
\text { work }\end{array}$ & $2.695(.374,19.431)$ \\
\hline Low back pain & Bent heavily with trunk & $4.923(.744,32.584)$ \\
\hline Low back pain & $\begin{array}{l}\text { Bent and twist simultane- } \\
\text { ously with trunk }\end{array}$ & $2.397(.537,10.698)$ \\
\hline Pain in elbow & $\begin{array}{l}\text { Hold the hands above the } \\
\text { shoulder level }\end{array}$ & $6.780(1.140,40.325)^{\star}$ \\
\hline Pain in wrist/ hand & $\begin{array}{l}\text { Hold the hands at or } \\
\text { under shoulder level }\end{array}$ & $1.097(.161,7.491)$ \\
\hline Pain in wrist/ hand & $\begin{array}{l}\text { Hold the hands above the } \\
\text { shoulder level }\end{array}$ & $1.184(.143,9.827)$ \\
\hline
\end{tabular}

* Statistically significant OR

\section{Discussion and conclusion}

This study has examined work-related musculoskeletal disorders among fifty surgeons from different sub-specialties working in a tertiary care hospital in Kathmandu, Nepal. The respondents were 40 male and 10 female surgeons with mean age of 38.9 years. Twenty-five surgeons had been working for less than 6 years as surgeons.

We found that thirty-five surgeons had at least one MSD, of which $60 \%$ surgeons complained of pain in lower back, $45 \%$ reported neck pain, and $34 \%$ reported elbow pain. Similarly, we found that twenty-three $(65.7 \%)$ of them missed their normal work at any time during last 12 month and nineteen (54.3\%) missed them during last 7 days.

We performed binary logistic regression to see the odds ratio for various MSDs and work related ergonomic hazards. It showed increased odds ratios for various MSDs due to exposure to various work related ergonomic hazards. But it was statistically significant only for elbow joint pain due to holding hands above the shoulder level [OR $(95 \% \mathrm{Cl}) 6.780$ (1.140, 40.325)].

Doctors have various occupational hazards. MSDs are important occupational health problems, especially for medical and dental surgeons due to static posture, repetitive movements, forceful exertions and precise hand and wrist movement during surgery $[8,9]$.

This study shows that MSD is very common among surgeons, of which lower back pain is the most common ailment. Previous study has also found that low back pain is a common health problem throughout the world which is a major cause of disability among professionals in different occupations[10]. A study involving 400 operating room assistants in the Netherlands reported that the prevalence of back pain was as high as $46 \%[11]$.A study conducted among 285 surgeons found 
that over $80 \%$ reported experiencing discomfort in the neck, shoulders and back areas [12]. A study conducted among the surgeons doing endourology and laparoscopic surgery revealed that more than $85 \%$ experienced musculoskeletal complaints in the past 12 months[13].

Ergonomics is the science of fitting work environment and job demands to the capability of the workers by designing tools, equipment, work stations and tasks to fit the job to the worker not the worker to the job [16]. The objective of ergonomics is to reduce stress and eliminate injuries and disorders associated with overuse of muscles, bad postures and repeated tasks. Risk factors include awkward postures, repetition, material handling, vibration, duration of exposure etc. Workers who spend many hours at a workstation may develop ergonomic-related problems resulting in musculoskeletal disorders (MSDs)[17]. Findings from this study have established association between different workplace ergonomic hazards and musculoskeletal disorders among the surgeons working in a tertiary care hospital in Kathmandu, Nepal. One can suspect that scenario could also be similar in other hospitals in Nepal. Therefore, work needs to be done to reduced ergonomic hazards in hospitals in order to prevent musculoskeletal disorders. This may be achieved by engineering controls and appropriate organizational arrangements. Our emphasis should be in reduction of the mechanical load on locomotor system during surgery, which is also an important measure for the prevention of musculoskeletal disorders [1]. We should think about holistic approach in management of musculoskeletal disorders. There are different techniques that can increase endurance to pain, reduce stress and anxiety levels. Regular physical activity could be very helpful in this regard. Role of practicing Yoga in improving physical and psychological elements, thereby minimizing musculoskeletal pain in doctors has been previously discussed [18].

This is the first research studying WRMSD among surgeons in Nepal, although the same has been studied among dentists previously $[14,15]$. This study was designed as a pilot study in a tertiary care hospital in Kathmandu, Nepal to assess prevalence of work related ergonomic hazards and associated musculoskeletal disorders among surgeons. Therefore, we included only 50 surgeons from different sub-specialties working in that hospital. Hence, we could not establish significance of association between risk factor and outcome. Although odds ratio for pain in elbow joint due to holding hands above shoulder level was statistically significant, 95\% confidence interval was wide due to small sample size. This is also a limitation of this study.

A multi-centre study involving a large group of surgeons and physicians from different specialties would be desirable to establish exact prevalence of workplace ergonomic hazards and associated MSDs.

\section{References}

1. Tirthankar Ghosh, Occupational Health and Hazards among Health Care Workers;International Journal of Occupational Safety and Health, Vol 3 No 1 (2013) 1-4.

2. Luttmann A, Jäger M, Griefahn B, Caffier G, Liebers F, Steinberg U. Preventing musculoskeletal disorders in the workplace. Protecting Workers' Health Series. No 5. Geneva: WHO; 2003.

3. Stewart WF, Ricci JA, Chee E, Morganstein D, Lipton R. Lost productive time and cost due to common pain conditions in the US workforce. JAMA. 2003;290:2443-54.

4. Smith DR, Wei N, Zhang YJ, Wang RS. Musculoskeletal complaints and psychosocial risk factors among physicians in mainland China. Int J IndErgon. 2006;36:599-603.

5. Hugo Piedrahita. Costs of Work-Related Musculoskeletal Disorders (MSDs) in Developing Countries: Colombia Case. International Journal of Occupational Safety and Ergonomics (JOSE) 2006; 12(4):379-386.

6. Hilderbrant, V.H., Bongers, P.M., van Dijk, F.J.H., Kemper, H.C.G. and J.Dul (2001) Dutch Musculoskeletal Questionnaire: description and basic qualities, Ergonomics, 44 (12), 1038-1055.

7. Kuorinka I1, Jonsson B, Kilbom A, Vinterberg H, BieringSørensen F, Andersson G, Jørgensen K. Standardised Nordic questionnaires for the analysis of musculoskeletal symptoms. Applied Ergonomics 1987, 18.3,233-237.

8. Szeto GP, Ho P, Ting AC, Poon JT, Cheng SW, Tsang RC. Work-related musculoskeletal symptoms in surgeons. J OccupRehabil. 2009;19:175-84.

9. Stomberg MW, Tronstad SE, Hedberg K, Bengtsson J, Jonsson $P$, Johansen $L$, et al. Work-related musculoskeletal disorders when performing laparoscopic surgery. SurgLaparoscEndoscPercutan Tech.2010;20:49-53.

10. Choobineh, A., Kasson, and Beek. , (2007). Musculoskeletal problems among workers of an Iranian communication company. Indian Journal of Occupational and Environmental Medicine, 11:32-36.

11. Meijsen P, Knibbe HJJ. Work-related musculoskeletal disorders of perioperative personnel in the Netherlands. AORN. 2007;86 (2):193-208.

12. (Wauben et al., 2006) Wauben LSGL, van Veelen MA, Gossot D, GoossensRHM.Application of ergonomic guidelines during minimally invasive surgery: a questionnaire survey of 284 surgeons. Surg Endosc.2006;20:1268-74 .

13. Irene M. Tjiam et al, Ergonomics in Endourology and Laparoscopy:An Overview of Musculoskeletal Problems in Urology.JOURNAL OF ENDOUROLOGY;Volume 28, Number 5, May 2014; DOI: 10.1089/end.2013.0654. 
14. Subham S, Yadav RP. Prevalence of low backache in practicing dentists of Eastern region of Nepal. Journal of Universal College of Medical Sciences 2013; 1(04);29-32.

15. Shrestha BP, Singh GK, Niraula SR. Work Related Complaints among Dentists. J Nepal Med Assoc 2008;47 (170):77-81.

16. Bernard BP, editor. U.S. Department of Health and Human Services, Centers for Disease control and Prevention, National Institute of Occupational Safety and Health. Musculoskeletal disorders and workplace factors: a critical review of epidemiologic evidence for work-related musculoskeletal disorders of the neck, upper extremity, and lower back. July 1997. DHHS (NIOSH) Publication No. 97-141. Available from: http://www.cdc.gov/niosh/docs/ $97-141 /$.

17. Centers for Disease Control and Prevention. Targeting arthritis: improving quality of Life for more than 46 million Americans, at-a-glance 2008. Atlanta, GA: U.S. Department of Health and Human Services, 2008.

18. Sharma P, Golchha V. Awareness among Indian dentist regarding the role of physical activity in prevention of work related musculoskeletal disorders. Indian J Dent Res. 2011; 22:381-4. 